\title{
Esclavage et littérature. Représentations francophones, dir. C. Chaulet Achour
}

\section{Elena Fermi}

\section{Q OpenEdition}

1 Journals

\section{Édition électronique}

URL : http://journals.openedition.org/studifrancesi/10610

DOI : 10.4000/studifrancesi. 10610

ISSN : 2421-5856

Éditeur

Rosenberg \& Sellier

\section{Édition imprimée}

Date de publication : 1 décembre 2017

Pagination : 590-591

ISSN : 0039-2944

\section{Référence électronique}

Elena Fermi, «Esclavage et littérature. Représentations francophones, dir. C. Chaulet Achour », Studi

Francesi [En ligne], 183 (LXI | III) | 2017, mis en ligne le 01 février 2018, consulté le 21 janvier 2021.

URL : http://journals.openedition.org/studifrancesi/10610 ; DOI : https://doi.org/10.4000/

studifrancesi. 10610

Ce document a été généré automatiquement le 21 janvier 2021.

\section{(c)}

Studi Francesi è distribuita con Licenza Creative Commons Attribuzione - Non commerciale - Non opere derivate 4.0 Internazionale. 


\title{
Esclavage et littérature. Représentations francophones, dir. C. Chaulet Achour
}

\author{
Elena Fermi
}

\section{RÉFÉRENCE}

Esclavage et littérature. Représentations francophones, sous la direction de Christiane CHAULET ACHOUR, Paris, Classiques Garnier, 2016, 267 pp.

1 Ce collectif réunit quinze contributions de chercheurs autour de la représentation littéraire des esclavages dans les littératures francophones extra-européennes qui prennent en compte la notion d'esclave telle qu'elle a été définie par Olivier Grenouilleau dans son ouvrage de 2014 Qu'est-ce que l'esclavage? Une histoire globale.

2 Le volume se divise en deux parties: «Visages divers des esclavages, du $\mathrm{IX}^{\mathrm{e}}$ au Xx $\mathrm{x}^{\mathrm{e}}$ siècle» regroupe six contributions, "Traite et esclavage transatlantique» en rassemble neuf. Les trois premières études concernent la représentation de l'esclavage dans l'univers arabo-musulman. Cyrille FRANçoIs s'occupe de la représentation des esclaves dans Les Mille et une Nuits. Après un petit aperçu historique de l'esclavage dans le monde musulman, l'auteur se concentre sur l'image de l'esclavage qui ressort des contes fantastiques du recueil, une image somme toute édulcorée, orientalisante qui a été assimilée, au fil des traductions, par l'imaginaire occidental. Christiane CHAULET ACHOUR se consacre à l'analyse du roman de Jamel-Eddine Bencheikh, Rose noire sans parfum, qui met en scène les Zandjs, les esclaves noirs «importés» en Mésopotamie au IX $\mathrm{x}^{\mathrm{e}}$ siècle de l'ère chrétienne pour assécher les marais du Bas Euphrate, et leur troisième révolte qui dura quinze ans. L'analyse de l'ouvrage permet au chercheur de mettre en relief la technique de cet écrivain et érudit qui ne donne qu'une fois, dans le prélude, la parole aux esclaves pour les laisser ensuite silencieux jusqu'à la fin et ne montrer que leurs gestes. Ce silence prolongé est un parti pris avec lequel l'écrivain veut souligner la 
condition de soumission complète des esclaves. Élodie GADEN se concentre, pour sa part, sur l'esclavage dans les harems d'Égypte à travers l'œuvre de Jehan d'Ivray. Le but est celui de s'interroger sur les représentations que cette écrivaine, femme, française et occidentale, propose de l'esclavage oriental. À travers l'analyse de ses œuvres on arrive à comprendre que, si condamnation il y a, le sujet reste extrêmement complexe du fait que le mode de vie du harem et la condition d'esclave ont souvent été intériorisés par ceux qui en sont concernés. Julie ASSIER nous emmène en Indochine au temps de la colonisation française et de la traite jaunière, analysée à travers l'œuvre d'Yvonne Schultz, en particulier le roman Dans la griffe des jauniers, paru en 1931. La romancière y met en scène, à travers la fiction, un univers où dominent injustice et oppression. La littérature contemporaine est à l'honneur dans l'article de Cécile JEST sur l'engagisme à Maurice. L'auteure choisit de dédier son étude au roman de Nathacha Appanah, Les Rochers de Poudre d'Or, où l'écrivaine retrace les grandes étapes du voyage des engagés indiens vers Maurice. Cet épisode fondateur pour la communauté indo-mauricienne est cependant porteur de problématiques pour la communauté afro-descendante, complètement déracinée par l'expérience de l'esclavage. Le but d'Appanah paraît bien être celui de mettre en relief la difficulté de relation entre ces deux communautés, qui continuent à être cloisonnées, tandis qu'elles devraient accepter l'idée de leur cohabitation et l'évidence d'une histoire commune. L'Étoile noire de Michelle Maillet fait l'objet de la contribution d'Émilie PATRIE qui analyse comment cette écrivaine conjugue dans son roman la mémoire de l'esclavage transatlantique et celle de la Shoah pour souligner le trait commun d'extrême déshumanisation dont ses deux expériences sont porteuses.

3 L'étude de Pierre-Louis FORT consacrée au récit de Maryse Condé, Chiens fous dans la brousse, ouvre la deuxième section du volume. L'esclavage est au cœur de cet ouvrage adressé au jeune public où l'absence de dénouement fait appel à la curiosité du jeune lecteur, invité à poursuivre lui-même la narration. CHAULET ACHOUR analyse le roman $L a$ saison d'ombre de la camerounaise Léonora Miano, qui explore le sujet de la traite en Afrique subsaharienne en s'interrogeant sur l'expérience qui a précédé la traversée de l'océan et le destin des esclaves au-delà de la mer. Elle propose ensuite une étude sur la manière dont Daniel Maximin traite de l'esclavage transatlantique et de ses effets dans la Caraïbe dans son roman L'Isolé Soleil, en faisant s'entrecroiser plusieurs voix afin d'observer les Antilles contemporaines à partir du passé et de l'ailleurs. FRANçoIs présente une contribution autour de l'un des poèmes fondateurs de la littérature antillaise, le Cahier d'un retour au pays natal, d'Aimé Césaire. Suivant l'auteur, Césaire problématise le sujet de l'esclavage, en l'ancrant à la fois dans l'imaginaire africain et dans des traditions littéraires européennes. Son poème est devenu ainsi une sorte d'incontournable pour tous les écrivains venus après. Marie FREMIN s'occupe du Quatrième siècle d'Édouard Glissant où le romancier martiniquais place l'histoire de l'esclavage au centre de son écriture. Selon le chercheur, la fiction glissantienne prendrait en charge le processus de réappropriation de l'histoire de l'esclavage qui devrait être assumée, interrogée et surtout transmise. Elle se concentre ensuite sur Moi, Tituba sorcière de Condé qui hisse au premier plan l'esclavage transatlantique afin d'évoquer le problème de la définition de l'identité antillaise et ouvre enfin un regard sur Haïti à travers le roman d'Évelyne Trouillot Rosalie l'Infâme où la romancière renouvellerait le regard sur l'esclavage et la connaissance que l'on peut en avoir. Chronique des sept misères de Chamoiseau unit, selon Maud VAULÉON, quête des origines et 
réappropriation d'une histoire collective. JEST analyse, dans l'article qui clôt l'ouvrage, L'Empreinte à Crusoé de Chamoiseau afin de montrer la révision originale que le romancier fait du célèbre mythe.

4 La riche section d'annexes en clôture du volume comprend plusieurs documents qui facilitent la consultation et le repérage d'informations à l'intérieur de l'ouvrage. On commence par une bibliographie assez complète des œuvres analysées et des références critiques, on continue avec un index des noms, des lieux et des notions, pour terminer avec une section dédiée à la présentation des différents auteurs des articles avec, pour chacun, un bref résumé de l'article lui-même, ce qui permet au lecteur une consultation rapide et un repérage facile de ce qui l'intéresse 